

\title{
Relative Risk of Hemorrhage during Pregnancy in Patients with Brain Arteriovenous Malformations
}

Janneke van Beijnum PhD, ${ }^{1,7}$ Tim Wilkinson MRCP, ${ }^{3}$ Heather J. Whitaker PhD, ${ }^{4}$ Johanna G. van der Bom PhD, ${ }^{8}$ Ale Algra PhD, ${ }^{1,2}$ W. Peter Vandertop PhD, ${ }^{5}$ René van den Berg PhD, ${ }^{6}$ Patrick A. Brouwer MD, ${ }^{9}$ Gabriël J.E. Rinkel PhD, ${ }^{1}$ L. Jaap Kappelle PhD,${ }^{1}$ Rustam Al-Shahi Salman PhD ${ }^{3}$ for the Scottish Audit of Intracranial Vascular Malformations collaborators, ${ }^{*}$ Catharina J.M. Klijn PhD ${ }^{1}$

Department of Neurology and Neurosurgery, ${ }^{1}$ Brain Center Rudolf Magnus, and the Julius Centre for Health Science and Primary Care, ${ }^{2}$ all at the University Medical Center Utrecht, P.O. Box 85500, 3508 GA, Utrecht, The Netherlands Division of Clinical Neurosciences, ${ }^{3}$ Centre for Clinical Brain Sciences, University of Edinburgh, Chancellor's Building, 49 Little France Crescent, Edinburgh EH16 4SB, United Kingdom

Department of Mathematics and Statistics, ${ }^{4}$ The Open University, Walton Hall, Milton Keynes MK7 6AA, United Kingdom Department of Neurosurgery ${ }^{5}$ and Radiology, ${ }^{6}$ Neurosurgical Center Amsterdam, VU University Medical Center and Amsterdam Medical Center, Amsterdam, P.O. Box 7057, 1007 MB, The Netherlands

Department of Neurosurgery, ${ }^{7}$ Clinical Epidemiology, ${ }^{8}$ and Radiology, ${ }^{9}$ Leiden University Medical Center, P.O. Box 9600, 2300 RC Leiden, The Netherlands

\section{CONTRIBUTIONS}

JVB, TW, WV, RvdB, PB, GR, LK, RA-SS, and CK were involved in the design of the study. JVB, RA-SS, and TW collected data. JvB, HW, JvdB, and AA were involved in the statistical analyses. JvB drafted the paper, and all coauthors reviewed and approved the final version.

\author{
CORRESPONDING AUTHOR \\ Janneke van Beijnum \\ Department of Neurosurgery \\ University Hospital of Wales \\ Heath Park \\ Cardiff CF14 4XW \\ Tel $\quad+442920745015$ \\ Fax $\quad+442920742560$ \\ Email J.vanBeijnum@gmail.com
}

WORD COUNT

2,510 (manuscript)

KEYWORDS

Arteriovenous malformation - Intracranial hemorrhage - Pregnancy - Self-controlled case-series 


\section{ABSTRACT}

Background - It is unclear whether the risk of bleeding from brain arteriovenous malformations (BAVMs) is higher during pregnancy, delivery or puerperium. We compared occurrence of BAVM hemorrhage in women during this period with occurrence of hemorrhage outside this period during their fertile years. Methods - We included all women with ruptured BAVMs (16-41 years) from a retrospective database of patients with BAVMs in four Dutch university hospitals $(n=95)$ and from the population-based Scottish Audit of Intracranial Vascular Malformations $(n=44)$. We estimated the relative rate of BAVM rupture (before any treatment) during exposed time (pregnancy, delivery, puerperium) versus nonexposed time during fertile years, using the case-crossover design as primary analysis, and the self-controlled case-series design as secondary analysis. Results - In 17 of 95 Dutch women and in 3 of 44 Scottish women, hemorrhages occurred while pregnant; none occurred during delivery or puerperium. In Dutch women, the relative rate of BAVM rupture during pregnancy, delivery, or puerperium was 6.8 (95\% confidence interval [Cl] 3.6-13) according to the case-crossover method and $7.1(95 \% \mathrm{Cl} 3.4-13)$ using the self-controlled case-series method. In Scottish women, the relative rate was $1.3(95 \% \mathrm{Cl} 0.39-4.1)$ using the case-crossover method and $1.7(95 \% \mathrm{Cl} 0.0-4.4)$ according to the self-controlled case-series method. Because of limited overlap of Cls we refrained from pooling the cohorts. Conclusions - Case-crossover and self-controlled case series analyses reveal an increase in relative rate of brain AVM rupture during pregnancy in the Dutch cohort but not in the Scottish cohort. Since point estimates varied between both cohorts and numbers are relatively small, the clinical implications of our findings are uncertain. 
Brain arteriovenous malformations (BAVMs) are abnormal connections between arteries and veins leading to arteriovenous shunting with an intervening network of vessels - the so-called nidus - and without a true capillary bed.(1,2) The most frequent presentation of BAVMs is intracranial hemorrhage, which has a peak incidence in the third and fourth decade.(3) Various case-reports and case-series of patients with BAVMs have reported the occurrence of hemorrhage during pregnancy.(4-7) One study on natural history reported that one in four women aged between 20 and 29 years, presenting with hemorrhage, were pregnant.(7) Some studies have suggested that women have an increased risk of hemorrhage during pregnancy,(8-10) whereas another study did not.(11) Investigating the effect of transient exposures such as pregnancy is methodologically challenging. Most previous studies compared hemorrhages rates during pregnant, and non-pregnant follow-up,(9-11) often in selected patient groups such as women referred for radiosurgery. $(10,11)$ In the past, incorrect interpretation of retrospective data in one study has led to recommendations to sterilize women with BAVMs. $(8,11)$ The effect of transient exposures on acute events can be studied with self-controlled methods, which use patients as their own controls in order to ascertain whether there is an association between a transient exposure and the acute event. Thus, confounding by variation in patients' characteristics can be avoided.(12-14) By means of two different self-controlled methods, we investigated in women with a ruptured BAVM whether the relative chance of rupture is higher during pregnancy, delivery, and puerperium than outside this period. 


\section{METHODS}

We estimated the relative rate of BAVM hemorrhage during pregnancy, delivery, and puerperium using a case-crossover design (Supplementary Figure I) as primary analysis, and according to the self-controlled case-series method (Supplementary Figure II) as secondary analysis.(12-14) Only the first BAVM hemorrhage during untreated follow-up was used (Supplementary Figures I and II). In both analyses we assumed a nine-month period (from the $7^{\text {th }}$ week after conception through the $6^{\text {th }}$ week after delivery) for the time at risk during pregnancy, delivery, and puerperium. The first six weeks of pregnancy were excluded because the hemodynamic changes in relation to pregnancy are less prominent during this time. Only the first BAVM hemorrhage during untreated follow-up was used in both analyses (Supplementary Figures I and II).

\section{PATIENTS}

We included all women with BAVM hemorrhage at fertile age (i.e. from 16 years up to and including 41 years), who were seen in one of four Dutch university hospitals (VUMC Amsterdam, AMC Amsterdam, Leiden UMC, and UMC Utrecht; inclusion period 1990-2006), or who were included in the population-based Scottish Audit of Intracranial Vascular Malformations study (SAIVMs; inclusion periods 1999-2003 and 2006-2010). The women in the Dutch hospitals were retrospectively identified through multiple, overlapping registries in each hospital to ensure that no patients were missed: stroke registries, diagnosis registration systems, pathology registries, operation registries, registries of embolized and radiosurgically treated patients, and neurovascular meetings. The SAIVMs is an on-going National Health Service clinical audit of adults who were aged 16 years or older and were resident in Scotland when 
first diagnosed with any type of intracranial vascular malformation. The Scottish Intracranial Vascular Malformations Study (SIVMS) is a prospective, populationbased cohort study in which anonymous data extracts from SAIVMs are used. Patients were identified through multiple overlapping sources of case ascertainment, which included a Scotland-wide collaborative network of neurologists, neurosurgeons, stroke physicians, radiologists, and pathologists, and central registers of hospital discharge records and death certificates.(15) The fertile period was defined from 16 years up to and including 41 years because in the general population $99 \%$ of pregnancies occur in women in this age range (Statistics Netherlands, www.statline.cbs.nl). The diagnosis of BAVM was confirmed with radiological or pathological examination. Patients who were diagnosed with hereditary hemorrhagic telangiectasias were excluded. BAVM hemorrhage was defined as a symptomatic clinical event, with signs of intracranial blood on brain imaging performed at the time of symptoms, lumbar puncture, or on post-mortem examination referable to the BAVM or an associated, flow-related aneurysm. All hemorrhages were classified as having occurred either during pregnancy, delivery, or puerperium, or outside this period.

In patients with a hemorrhage during pregnancy, delivery, or puerperium, we retrieved information on maternal age, gestational age at the time of hemorrhage, mode of delivery, location and treatment of the BAVM, and maternal (according to the Glasgow Outcome Scale(16)) and fetal outcome.

\section{Maternity Data}

For women in the Dutch cohort, we used information regarding live-born children that was given by patients who participated in a survey to investigate familial occurrence of BAVMs,(17) and information retrieved from the medical files. 
For women in the Scottish cohort, obstetric episodes were obtained from the maternity inpatient, and day-case discharges data set by the Information Services Division (ISD) in the Scottish Morbidity Records (SMR02). The ISD has consistently achieved a national coverage of $98 \%$ of all births (www.isdscotland.org/HealthTopics/Maternity-and-Births/Births/). The SMR02 maternity data were cross-checked with any information about previous pregnancies in the case records of the women. If a patient, who met the inclusion criteria, did not link with the SMR02 dataset her case records were searched for references to any children or previous pregnancies. In most cases, these women had never been pregnant. For the women who did not link with the SMR02 dataset, and whose case records suggested existing children, the patient or her GP was contacted and asked to provide the delivery dates and gestations of her children.

In both Dutch and Scottish women abortions and miscarriages were not taken into account.

\section{Statistical Analysis}

First, we estimated the relative hemorrhage rates during pregnancy, delivery, or puerperium, and during non-exposed time, restricting the duration of follow-up to the time until the first hemorrhage, for the total cohort and the Dutch and Scottish cohorts separately. Subsequently, the relative rate of BAVM hemorrhage during pregnancy, delivery, and puerperium was estimated using the case-crossover design as primary analysis, and the self-controlled case-series method as secondary analysis.(12-14) We planned to analyze the Dutch and Scottish cohorts separately, and subsequently combined.

In the case-crossover analysis (Supplementary Figure I), we expressed the time at risk of a woman until occurrence of her first hemorrhage during her fertile years in "9- 
months' periods" by multiplying the number of years by $12 / 9$ yielding relative rates with 95\% confidence intervals (Cls). Analyses were performed with SPSS (version 20).

In the self-controlled case-series analysis (Supplementary Figure II), we studied the first hemorrhage because hemorrhage may affect subsequent exposure (e.g. a woman may die after hemorrhage or may be advised against pregnancy). We used the extension to the self-controlled case-series method for censored, perturbed or curtailed post-event exposures to obtain unbiased relative rate estimates.(14) Analyses were performed using STATA (Version 8.1). Cls were estimated using bootstrapping.

\section{Review of the literature}

We searched PubMed for case-series and systematic reviews reporting on women with BAVMs and their hemorrhage risk during pregnancy, delivery, and puerperium published in English on September 1st, 2016, with the search terms (intracranial arteriovenous malformations OR brain arteriovenous malformations) AND intracranial hemorrhage AND pregnancy.

\section{Ethical approval}

The Dutch study was approved by the institutional ethical committee of the University Medical Center Utrecht.(17) The Multicenter Research Ethics Committee for Scotland (MREC/98/0/48) and the Fife and Forth Valley Research Ethics Committee (08/S0501/76) approved the under taking of observational studies (to which an optout consent policy applied) and postal questionnaire studies (which required opt-in consent). 


\section{RESULTS}

In $95(28 \%)$ of 340 women in the Dutch and in $44(22 \%)$ of 202 women in the Scottish cohort, hemorrhage occurred during their fertile lives (Table 1).

With respect to case-ascertainment in the Scottish cohort, three patients were reported by ISD only and not by one of the Scottish neuroscience centers. One of these three women experienced BAVM hemorrhage during her pregnancy (Table 2). On average, women in the Dutch cohort were slightly older than women in the Scottish cohort (observed difference 3.0 years, $95 \% \mathrm{Cl} 0.62-5.4$ ) at the time they gave birth to their first child. The proportion of lobar BAVMs was higher in the Scottish cohort (observed difference 21\%, 95\% Cl 4.6-38).

\section{Dutch cohort}

Seventeen women experienced BAVM hemorrhage during 56 years at risk (relative hemorrhage rate $30 \% / y e a r, 95 \% \mathrm{Cl} 18-49 \%$ ), and in 78 women $\mathrm{BAVM}$ rupture occurred during 1,231 non-pregnant person years (relative hemorrhage rate 6.3 \%/year, 95\% $\mathrm{Cl} 5.0-7.9 \%)$. The case-crossover method yielded a relative rate during pregnancy, delivery, or puerperium of $6.8(95 \% \mathrm{Cl}, 3.6-13)$, and the self-controlled case-series of $7.1(95 \% \mathrm{Cl}, 3.4-13)$.

\section{Scottish cohort}

Three women experienced a hemorrhage during a total of 35 years at risk (relative hemorrhage rate $8.6 \% / y e a r, 95 \% \mathrm{Cl} 1.8-25 \%$ ), and 41 hemorrhages occurred during 597 non-pregnant person years (relative hemorrhage rate $6.9 \% / y e a r, 95 \% \mathrm{Cl} 4.9$ 9.3\%). The case-crossover method yielded a relative rate during pregnancy, delivery, or puerperium of $1.3(95 \% \mathrm{Cl}, 0.39-4.1)$, and the self-controlled case-series a relative rate of $1.7(95 \% \mathrm{Cl}, 0.0-4.4)$. 


\section{Combined cohort}

Given the limited overlap of the Cls of the point estimates, we refrained from pooling both cohorts.

\section{Review of the literature}

We identified five case-series(8-11,18) and two systematic reviews (Table 3).(4,19) Two narrative reviews were excluded.(20,21) The most recent case-series - using a self-controlled method in large hospital-based, retrospective Chinese cohort showed a decreased hemorrhage risk associated with pregnancy, delivery, and puerperium.(19) Another retrospective study concluded that the hemorrhage risk during pregnancy was not increased,(11) whereas two studies showed an increased risk of BAVM hemorrhage during pregnancy(9) or during the second trimester only.(10) 


\section{DISCUSSION}

In the Dutch hospital cohort of women with a ruptured BAVM the relative rupture rate was approximately seven times higher during pregnancy, delivery, and puerperium than outside this period. The analyses in the smaller population-based Scottish cohort did not confirm this increased risk. Limited overlap of the Cls of the point estimates hampered the pooled analysis.

The observed difference in hemorrhage risk during pregnancy, delivery and puerperium between the Dutch and Scottish cohorts may have been due to chance, especially given the sample sizes. Still, referral bias may have played a role. One would think that a woman with BAVM hemorrhage is more likely to get referred to a neuroscience center if she is pregnant. Yet, one Scottish woman who experienced a BAVM hemorrhage during pregnancy was only reported to the researchers by the ISD but not by one of the collaborating neuroscience centers. In the Netherlands, we would expect that all young women with BAVM hemorrhage are referred to a neurosurgical center unless they have died in a local hospital. Geographic or ethnic differences are unlikely to explain the disparate risk during pregnancy, delivery and puerperium as both in The Netherlands and Scotland, the large majority of the women were Caucasian. Moreover, hemorrhage rates outside pregnancy were similar in both cohorts (6.3\%/year vs. 6.9\%/year), which makes it also unlikely that the higher proportion of women with lobar BAVMs included in the Scottish cohort explains the observed difference in hemorrhage risk during pregnancy.

A recent Chinese hospital-based study showed a decreased hemorrhage risk during pregnancy using the case-crossover method.(18) In this study, the relative hemorrhage rate during pregnancy, delivery and puerperium $(2.7,12$ 
hemorrhages/452 pregnancies; Supplementary Figure III) was remarkably low in comparison to the Dutch $(18,17$ hemorrhages/95 pregnancies) and to the Scottish (6.8, 3 hemorrhages/44 pregnancies) cohort. The relative hemorrhage rate outside pregnancy was also lower (4.1\%/year) in the Chinese study than in the Dutch (6.3\%/year) and Scottish (6.9\%/year) cohorts. The Chinese women were enrolled over a large time frame between 1960 and 2010, and diagnosis of both hemorrhage and BAVM is likely to have been less accurate in the earlier decades. Also, the fact that the authors included 54 patients with previous hemorrhage or BAVM treatment may have influenced their hemorrhage risk as well as the decision to become pregnant in some women, and therefore biased their results.(18) Another study, which analyzed the effect of pregnancy using Cox proportional hazards regression modelling with pregnancy as time-dependent co-variable, yielded an almost eight times increased risk of BAVM hemorrhage during pregnancy.(9) This is comparable to the results found in the Dutch cohort.

An important strength of our study is that we used two self-controlled methods(12-14) which yielded similar results. We added the self-controlled case-series as a secondary analysis because of increased power in comparison to the case-crossover design, and the possibility to explicitly control for age- and time-related effects.(14) Additionally, we censored women at the time of first hemorrhage because the rupture rate increases after a first hemorrhage, and the occurrence of BAVM hemorrhage may influence the decision to become pregnant. Moreover, our cohorts were not limited to patients who were referred for a certain treatment as in some previous studies, $(10,11)$ and we calculated the risk-time from the age of 16 years and not from birth.(11) 
Our study is limited by the small number of included women despite our efforts to improve power by combing cohorts. Secondly, case-ascertainment differed between the Dutch and Scottish cohorts, which could have contributed to the different results during pregnancy. Thirdly, in both cohorts pregnant follow-up may have been underestimated by not including abortions and miscarriages. Additionally, pregnancies may have been missed by the ISD in Scotland, and the Dutch women might not have declared all of their pregnancies when asked. Finally, an important limitation of our study with respect to clinical applicability is that with the data we had we could calculate relative but no absolute risks of rupture during pregnancy, delivery, and puerperium. Moreover, risks for women with unruptured BAVMs cannot be deducted from our results. It is important to realize that all women included in our study bled, and that in the majority of women hemorrhage was the first presentation of their BAVMs (95\% Dutch cohort, 98\% Scottish cohort; Table 1).

Although our study cannot provide the final answers, which are needed for clinical practice, the results from the Dutch cohort support previous observations that the period of pregnancy, delivery and puerperium could increase the risk of BAVM rupture in particular with increasing gestational age. Women with a BAVM should be informed of the possibility that pregnancy probably increases the risk of BAVM hemorrhage, but that the extent to which this occurs is uncertain. Given the annual hemorrhage risk of $2.3-3.0 \%$ per year, $(22,23)$ a temporary increase during pregnancy by $\sim 1.5$ as found in the Scottish cohort would not infer a considerably larger risk whereas an increase by $\sim 7$ would denote a clinically significant increased hemorrhage risk. Whether or not an unruptured BAVM should be treated before conception will depend on the characteristics of the BAVM, the individualized estimated risk of hemorrhage and treatment, and the informed opinion of the patient. 
The short-term results of the ARUBA trial - showing a more than three-fold increased risk of stroke and death after intervention compared with conservative management in patients with unruptured BAVMs - have to be taken into account as well as the criticisms with respect to the conduct and outcome of this trial. $(24,25)$ In our view, there is no reason to advise discontinuation of pregnancy or sterilization as has been done in the past.

Ideally, the effect of pregnancy on the hemorrhage risk of BAVMs should be investigated by the conduct of large multi-center prospective population-based studies because these will provide absolute risks during pregnancy for all women with BAVMs. Meanwhile, replication of this study design in larger prospectively population-cohorts or individual patient data meta-analysis studies can add to the current findings. 
Funding Janneke van Beijnum was funded by the Netherlands Organization for Scientific Research and the Netherlands Heart Foundation (grant number 2002B138). Rustam Al-Shahi Salman was funded by the UK Medical Research Council, Chief Scientist Office of the Scottish Government, and UK Stroke Association. Catharina Klijn was funded by the Netherlands Heart Foundation (Clinical Established Investigator Grant 2012T077) and the Netherlands Organization for Scientific Research (ZonMw, Aspasia grant 015008048). The sponsors had no role in the study design, data collection, data analyses, data interpretation or writing of the report.

Conflict of interests P.A. Brouwer (Stryker, honoraria and consultant/advisory relationship; modest). The other authors declare no conflicts of interest. 


\section{REFERENCES}

(1) Geibprasert S, Pongpech S, Jiarakongmun P et al. Radiologic assessment of brain arteriovenous malformations: what clinicians need to know. Radiographics 2010;30:483-501.

(2) Friedlander RM. Clinical practice. Arteriovenous malformations of the brain. $\mathrm{N}$ Engl J Med 2007;356:2704-12.

(3) Al Shahi Salman R, Warlow C. A systematic review of the frequency and prognosis of arteriovenous malformations of the brain in adults. Brain 2001;124:1900-26.

(4) Dias MS, Sekhar LN. Intracranial hemorrhage from aneurysms and arteriovenous malformations during pregnancy and the puerperium. Neurosurgery 1990;27:855-65.

(5) Velut S, Vinikoff L, Destrieux C et al. [Cerebro-meningeal hemorrhage secondary to ruptured vascular malformation during pregnancy and post-partum]. Neurochirurgie 2000;46:95-104.

(6) Kelly DL, Jr., Alexander E Jr, Davis $\mathrm{CH}$, et al. Intracranial arteriovenous malformations: clinical review and evaluation of brain scans. J Neurosurg 1969;31:422-8.

(7) Crawford PM, West CR, Chadwick DW, et al. Arteriovenous malformations of the brain: natural history in unoperated patients. J Neurol Neurosurg Psychiatry 1986;49:1-10.

(8) Robinson JL, Hall CS, Sedzimir CB. Arteriovenous malformations, aneurysms, and pregnancy. J Neurosurg 1974;41:63-70.

(9) Gross BA, Du R. Hemorrhage from arteriovenous malformations during pregnancy. Neurosurgery 2012;71:349-55.

(10) Forster DM, Kunkler IH, Hartland P. Risk of cerebral bleeding from arteriovenous malformations in pregnancy: the Sheffield experience. Stereotact Funct Neurosurg 1993;61 Suppl 1:20-2.

(11) Horton JC, Chambers WA, Lyons SL, et al. Pregnancy and the risk of hemorrhage from cerebral arteriovenous malformations. Neurosurgery 1990;27:867-71.

(12) Maclure M. The case-crossover design: a method for studying transient effects on the risk of acute events. Am J Epidemiol 1991;133:144-53.

(13) Whitaker HJ, Hocine MN, Farrington CP. The methodology of self-controlled case series studies. Stat Methods Med Res 2009;18:7-26.

(14) Farrington $\mathrm{CP}$, Whitaker $\mathrm{HJ}$, Hocine $\mathrm{MN}$. Case series analysis for censored, perturbed, or curtailed post-event exposures. Biostatistics 2009;10:3-16.

(15) Al Shahi Salman R, Bhattacharya JJ, Currie DG, et al. Scottish Intracranial Vascular Malformation Study: evaluation of methods, ICD-10 coding, and potential sources of bias in a prospective, population-based cohort. Stroke 2003;34:1156-62.

(16) Jennett B, Bond M. Assessment of outcome after severe brain damage. Lancet 1975;1:480-4.

(17) van Beijnum J, van der Worp HB, Algra A, et al. Prevalence of Brain Arteriovenous Malformations in First-Degree Relatives of Patients With a Brain Arteriovenous Malformation. Stroke 2014;45:3231-5.

(18) Liu XJ, Wang S, Zhao YL, et al. Risk of cerebral arteriovenous malformation rupture during pregnancy and puerperium. Neurology 2014;82:1798-803. 
(19) LV X, Liu P, Li Y. Pre-existing, incidental and hemorrhagic AVMs in pregnancy and postpartum: Gestational age, morbidity and mortality, management and risk to the fetus. Neuroradiol J. 2016;22:206-11.

(20) Agarwal N, Guerra JC, Gala N, et al. Current Treatments Options for Cerebral Arteriovenous Malformations in Pregnancy: A Review of the Literature. World Neurosurg 2014;81:83-90.

(21) LV X, Liu P, Li Y. The clinical characteristics and treatment of cerebral AVM in pregnancy. Neuroradiol J. 2015;28:234-7.

(22) Kim H, Al-Shahi Salman R, McCulloch CE, et al. Untreated brain arteriovenous malformation: patient-level meta-analysis of hemorrhage predictors. Neurology 2014;83:590-7.

(23) Gross BA, Du R. Natural history of cerebral arteriovenous malformations: a meta-analysis J Neurosurg 2013;118:437-43.

(24) Mohr JP, Parides MK, Stapf $C$ et al. Medical management with or without interventional therapy for unruptured brain arteriovenous malformations (ARUBA): a multicentre non-blinded randomised trial. Lancet 2014; 383:614-621

(25) Meling TR, Proust F, Gruber A, et al. On apples, oranges, and ARUBA. Acta Neurochir (Wien) 2014;156:1775-9. 


\begin{tabular}{|c|c|c|}
\hline & Dutch Cohort & Scottish Cohort \\
\hline Number of patients & 95 & 44 \\
\hline \multicolumn{3}{|l|}{ Initial BAVM presentation } \\
\hline Ruptured & $90(95 \%)$ & $43(98 \%)$ \\
\hline Unruptured & $5(5.3 \%)$ & $1(2.3 \%)$ \\
\hline \multicolumn{3}{|l|}{ Age at first hemorrhage (years) } \\
\hline Mean (SD) & $29(7.3)$ & $30(7.7)$ \\
\hline Age at birth of first child (years) & $n=48$ & $n=27$ \\
\hline Mean (SD) & $26(4.7)$ & $23(5.4)$ \\
\hline \multicolumn{3}{|l|}{$\begin{array}{l}\text { Number of pregnancies at first } \\
\text { hemorrhage* }^{*}\end{array}$} \\
\hline 0 & $51(54 \%)$ & $19(43 \%)$ \\
\hline 1 & $21(22 \%)$ & $9(21 \%)$ \\
\hline 2 & $18(19 \%)$ & $11(25 \%)$ \\
\hline 3 & $4(4.2 \%)$ & $5(11 \%)$ \\
\hline 4 & 0 & 0 \\
\hline 5 & $1(1.1 \%)$ & 0 \\
\hline \multicolumn{3}{|l|}{ BAVM Location } \\
\hline Lobar & $49(52 \%)$ & $32(73 \%)$ \\
\hline Deep & $27(28 \%)$ & $8(18 \%)$ \\
\hline Infratentorial & $19(20 \%)$ & $4(9.1 \%)$ \\
\hline \multicolumn{3}{|c|}{$\begin{array}{l}\text { * Cumulative number of previous pregnancies (including current pregnancy if } \\
\text { BAVM rupture occurred during pregnancy) prior to the date of first-ever BAVM } \\
\text { hemorrhage. }\end{array}$} \\
\hline
\end{tabular}




\begin{tabular}{|c|c|c|c|c|c|c|c|c|}
\hline & Age & G/P & GA & Location BAVM & Delivery & Treatment BAVM & $\begin{array}{l}\text { Maternal } \\
\text { outcome }\end{array}$ & $\begin{array}{l}\text { Child's } \\
\text { outcome }\end{array}$ \\
\hline \multicolumn{9}{|c|}{ Dutch cohort } \\
\hline \multirow[t]{2}{*}{1} & 30 & G1P0 & 34 & Thalamus $\mathrm{R}$ & CS & SRS1 & GOS 5 & Healthy \\
\hline & $33 \dagger$ & G2P1 & 32 & & CS & SRS2 & GOS 5 & Healthy \\
\hline 2 & 30 & G1P0 & 27 & Frontal R & Vaginal & Excision & GOS 5 & IUFD \\
\hline 3 & 33 & G3P2 & 41 & Parietal R & CS & Embolization, RS & GOS 5 & Healthy \\
\hline 4 & 32 & G1P0 & 32 & Parietal L & CS & Excision & GOS 4 & Healthy \\
\hline 5 & 27 & G3P2 & 20 & Mesencephalon L & CS & SRS & GOS 4 & Healthy \\
\hline 6 & 25 & G1P0 & 38 & Temporal R & $\mathrm{CS}$ & Excision & GOS 5 & Healthy \\
\hline 7 & 29 & G1P0 & 24 & Corpus callosum R & CS & SRS & GOS 5 & Healthy \\
\hline 8 & 19 & G1P0 & 22 & Occipital L & CS & SRS & GOS 5 & Healthy \\
\hline 9 & 18 & G1P0 & 24 & Frontal L & CS & SRS & GOS 5 & Healthy \\
\hline 10 & 25 & G1P0 & 24 & Cerebellum R & $U$ & SRS & GOS 5 & Healthy \\
\hline 11 & 34 & G2P1 & 12 & Multilobar L & Vaginal & SRS & GOS 3 & Healthy \\
\hline 12 & 24 & G1P0 & 31 & Parietal L & Cs & $\begin{array}{l}\text { Partial Excision, } \\
\text { SRS }\end{array}$ & GOS 5 & Healthy \\
\hline $13^{*}$ & 33 & G2P1 & 28 & Paraventricular $\mathrm{R}$ & CS & SRS & GOS 3 & Healthy \\
\hline 14 & 33 & G2P1 & 33 & Basal ganglia R & CS & None & GOS 1 & Healthy \\
\hline 15 & 35 & G1P0 & 28 & Frontal L & Vaginal & Excision & GOS 5 & Healthy \\
\hline 16 & 22 & G1P0 & 23 & Frontal R & Vaginal & Excision & GOS 5 & Healthy \\
\hline 17 & 24 & G1P0 & 28 & Occipital L & CS & Excision & GOS 5 & Healthy \\
\hline \multicolumn{9}{|c|}{ Scottish Cohort } \\
\hline 1 & 34 & $\mathrm{G} 2 \mathrm{P} 1$ & 30 & Multilobar R & CS & Excision & GOS 4 & Healthy \\
\hline 2 & 26 & G2P1 & 22 & Multilobar L & U & Excision & GOS 4 & IUFD \\
\hline $3 \neq$ & 30 & G1P0 & 7 & Insula L & CS & SRS & GOS 4 & Healthy \\
\hline \multicolumn{9}{|c|}{$\begin{array}{l}\text { CS, Caesarean section; G, Gravidity; GA, Gestational age in weeks; GOS, Glasgow Outcome Scale; P, Parity; SRS, } \\
\text { Stereotactic radiosurgery; U, Unknown; IUFD, Intrauterine Fetal Death. } \\
\text { ^ Excluded from the secondary analysis because the exact date of birth of her first child was unknown which was } \\
\text { mandatory for the self-controlled case series but not for the case-crossover design. } \\
\text { † Second hemorrhage is not included in the analyses. } \\
\text { ‡ ISD notification only }\end{array}$} \\
\hline
\end{tabular}




\begin{tabular}{|c|c|c|c|c|}
\hline Author & $\begin{array}{l}\text { Study } \\
\text { population }\end{array}$ & Methods and analysis & Results & Conclusion \\
\hline $\begin{array}{l}\text { Robinson } \\
1974\end{array}$ & $\begin{array}{l}\text { Hospital-based } \\
152 \text { women aged } \\
<45 \text { yrs } \\
\text { diagnosed with } \\
\text { BAVM ( } n=33 \text { ) or } \\
\text { aneurysm } \\
\text { ( } n=113 \text { ) by DSA } \\
\text { or at autopsy } \\
\text { between 1954- } \\
1970\end{array}$ & $\begin{array}{l}\text { Retrospective case- } \\
\text { series } \\
\text { Comparison of } \\
\text { causative vascular } \\
\text { lesion in group } 1 \\
\text { (presented < } 2 \text { yrs after } \\
\text { pregnancy, during } \\
\text { pregnancy, delivery, } \\
\text { puerperium, or if } \\
\text { pregnancy followed } \leq 2 \\
\text { yrs after presentation) } \\
\text { and group } 2 \text { (not } \\
\text { associated with } \\
\text { pregnancy). }\end{array}$ & $\begin{array}{l}\text { Follow-up in } 146 \text { pts ( } 96 \%) \text {. Group } 1 \\
\text { (67 pts) included } 24 \text { pts ( } 36 \% \text { ) with } \\
\text { BAVMs and } 43(64 \%) \text { pts with } \\
\text { aneurysms. } 21 / 24 \text { BAVM pts } \\
\text { presented with SAH, and 11/21 pts } \\
\text { bled during pregnancy. } 47 \\
\text { pregnancies occurred in } 24 \text { BAVM pts } \\
\text { resulting in } 35 \text { live-born children. } \\
\text { Group } 2 \text { (79 pts) included } 9 \text { patients } \\
\text { (11\%) with BAVMs and } 70 \text { (89\%) with } \\
\text { aneurysms. Only } 1 / 9 \text { BAVM pts } \\
\text { presented with SAH. Hemorrhage } \\
\text { usually occurred between weeks 16- } \\
24 \text {, shortly before labor, during } \\
\text { delivery, or in early puerperium. }\end{array}$ & $\begin{array}{l}\text { BAVMs were diagnosed in } 36 \% \text { of } \\
\text { women who presented in association } \\
\text { with pregnancy, which was } 4 \text { times } \\
\text { higher than the overall numbers } \\
(9 \%) \text { A BAVM pt who never } \\
\text { becomes pregnant has a relatively } \\
\text { low risk of SAH; however if a woman } \\
\text { does become pregnant the chances } \\
\text { increase to } 87 \% \text {. [Our interpretation: } \\
\text { if a BAVM is diagnosed in } \\
\text { association with pregnancy, this will } \\
\text { be due to hemorrhage in } 87 \% \text { of pts.] }\end{array}$ \\
\hline $\begin{array}{l}\text { Dias }^{4} \\
1990\end{array}$ & $\begin{array}{l}\text { Case-reports } \\
\text { published } \\
\text { between } 1947- \\
1988\end{array}$ & $\begin{array}{l}\text { Review of English } \\
\text { literature } \\
\text { Including all reported } \\
\text { cases of verified } \\
\text { hemorrhage during } \\
\text { pregnancy and } \\
\text { puerperium }\end{array}$ & $\begin{array}{l}36 \text { pts (mean age } 27 \text { yrs) with BAVM } \\
\text { hemorrhage during pregnancy, of } \\
\text { whom } 2 \text { during labor and delivery. } \\
26 \% \text { of women were nulliparous. } \\
\text { Mean GA } 30 \text { weeks. Maternal } \\
\text { mortality } 28 \% \text {. Fetal mortality } 14 \% \text {. }\end{array}$ & $\begin{array}{l}\text { BAVMs bleed more frequently } \\
\text { with advancing GA, possibly due } \\
\text { to hemodynamic changes of } \\
\text { pregnancy. Two women with } \\
\text { BAVMs bled during labor and } \\
\text { delivery. }\end{array}$ \\
\hline $\begin{array}{l}\text { Horton }^{11} \\
1990\end{array}$ & $\begin{array}{l}\text { Hospital-based } \\
451 \text { women with } \\
\text { a BAVM aged } \geq \\
18 \text { yrs diagnosed } \\
\text { with BAVMs } \\
\text { referred for } \\
\text { radiosurgery } \\
\text { between 1977- } \\
1986\end{array}$ & $\begin{array}{l}\text { Retrospective case- } \\
\text { series } \\
\text { Hospital records } \\
\text { supplemented by written } \\
\text { questionnaire. } \\
\text { Annual hemorrhage } \\
\text { rates: ratio of number of } \\
\text { bleeds to pt-yrs during } \\
\text { pregnant and non- } \\
\text { pregnant FU from birth } \\
\text { to treatment. }\end{array}$ & $\begin{array}{l}451 \text { women experienced } 459 \\
\text { hemorrhages during } 14,235 \text { pts-yrs, } \\
\text { i.e. } 3.2 \% / \text { pt-yr. } \\
540 \text { pregnancies ( } 468.6 \text { pt-yrs) } \\
\text { occurred in } 238 \text { pts. } 17 \text { hemorrhages } \\
\text { occurred during pregnancy, i.e. } \\
3.6 \% / \text { pt-yr: } 4(18 \%) \text { in } 1^{\text {st }} \text { trim, } 7 \\
(41 \%) \text { in } 2^{\text {nd }} \text { trim, } 5(29 \%) \text { in } 3^{\text {rd }} \text { trim } \\
\text { and } 2(12 \%) \text { in puerperium. } 445 \\
\text { hemorrhages occurred outside } \\
\text { pregnancy, i.e. } 3.2 \% / p t-y r .\end{array}$ & $\begin{array}{l}\text { Risk of non-fatal BAVM during } \\
\text { pregnancy was } 3.5 \% / p t-y r \text { for pts } \\
\text { with untreated BAVMs if no } \\
\text { history of previous hemorrhage. }\end{array}$ \\
\hline $\begin{array}{l}\text { Forster }^{10} \\
1993\end{array}$ & $\begin{array}{l}\text { Hospital-based } \\
191 \text { women with } \\
\text { a BAVM aged 15- } \\
45 \text { years referred } \\
\text { between } 1985 \\
\text { and } 1991 \text { for } \\
\text { radiosurgery }\end{array}$ & $\begin{array}{l}\text { Retrospective case- } \\
\text { series } \\
\text { Hospital records } \\
\text { supplemented by written } \\
\text { questionnaire. } \\
\text { Annual hemorrhage } \\
\text { rates: ratio of number of } \\
\text { bleeds to pt-yrs during } \\
\text { pregnant and non- } \\
\text { pregnant FU during } \\
\text { fertile age. }\end{array}$ & $\begin{array}{l}229 \text { pregnancies (162 pt-yrs) } \\
\text { occurred in } 116 \text { women. } 35 \text { women } \\
\text { never bled. } 207 \text { hemorrhages } \\
\text { occurred during } 2,431 \text { pts-yrs, i.e. } \\
8.5 \% / \text { pt-yr. } 14 \text { hemorrhages occurred } \\
\text { during pregnancy }(162 \text { pt-yrs), i.e. } \\
8.6 \% / \text { pt-yr. } 3(20 \%) \text { hemorrhages } \\
\text { occurred in } 1^{\text {st }} \text { trim, } 9(60 \%) \text { in } 2^{\text {nd }} \\
\text { trim, } 3(20 \%) \text { in third trim, but none } \\
\text { during delivery, CS or in puerperium. } \\
\text { Hemorrhage rate was unchanged in } \\
1^{\text {st }}(5.3 \% / y r), 3^{\text {rd }}(5.8 \% / y r) \text { trim, } \\
\text { increased in } 2^{\text {nd }} \text { trim }(17 \% / y r) \text {. }\end{array}$ & $\begin{array}{l}\text { Risk of BAVM hemorrhage is } \\
\text { increased in } 2^{\text {nd }} \text { trimester of } \\
\text { pregnancy. }\end{array}$ \\
\hline $\begin{array}{l}\text { Gross }^{9} \\
2012\end{array}$ & $\begin{array}{l}\text { Hospital-based } \\
58 \text { women with a } \\
\text { DSA-confirmed } \\
\text { diagnosis of } \\
\text { BAVM between } \\
\text { 2002-2010 }\end{array}$ & $\begin{array}{l}\text { Retrospective case- } \\
\text { series } \\
\text { Annual hemorrhage } \\
\text { rates: ratio of number of } \\
\text { bleeds to pt-yrs during } \\
\text { pregnant and non- } \\
\text { pregnant FU during } \\
\text { fertile age. } \\
\text { Cox proportional } \\
\text { hazards regression } \\
\text { model with pregnancy } \\
\text { as time-dependent } \\
\text { covariate and } \\
\text { hemorrhage as } \\
\text { censoring event. }\end{array}$ & $\begin{array}{l}54 \text { women - with known parturient } \\
\text { status - experienced a total of } 62 \\
\text { pregnancies. } 4 \text { women experienced } 5 \\
\text { hemorrhages while pregnant. Annual } \\
\text { hemorrhage rate during pregnancy: } \\
11 \% / \text { patient year during pregnant } \\
\text { time. HR for pregnancy was } 7.9 \text { ( } 95 \% \\
\mathrm{Cl} 2.6-24) \text {. One hemorrhage occurred } \\
\text { in } 2^{\text {nd }} \text { trim, and } 4 \text { hemorrhages } \\
\text { occurred in } 3^{\text {rd }} \text { trim. }\end{array}$ & $\begin{array}{l}\text { Elevated risk of hemorrhage from } \\
\text { BAVMs during pregnancy in } \\
\text { comparison with non-pregnant } \\
\text { time. }\end{array}$ \\
\hline $\begin{array}{l}\operatorname{Liu}^{18} \\
2014\end{array}$ & $\begin{array}{l}\text { Hospital-based } \\
979 \text { women with } \\
\text { DSA- or PE- } \\
\text { confirmed } \\
\text { diagnosis of } \\
\text { BAVM between } \\
\text { 1960-2010. }\end{array}$ & $\begin{array}{l}\text { Retrospective analysis } \\
\text { of prospectively } \\
\text { collected-database } \\
\text { CCO analysis including } \\
393 \text { women with BAVM } \\
\text { hemorrhage at age } \\
\text { between 18-40 yrs }\end{array}$ & $\begin{array}{l}\text { Six bleeds occurred in } 2^{\text {nd }} \text { trim, } 5 \\
\text { hemorrhages in } 3^{\text {rd }} \text { trim, and one } \\
\text { in puerperium. } \\
\text { Relative rate } 0.71(95 \% \mathrm{Cl} 0.61-0.82) \text {. }\end{array}$ & $\begin{array}{l}\text { Decreased risk of hemorrhage } \\
\text { from BAVMs during pregnancy } \\
\text { and puerperium }\end{array}$ \\
\hline$L x^{19}$ & $\begin{array}{l}\text { Case-reports of } \\
\text { verified } \\
\text { hemorrhage } \\
\text { during pregnancy } \\
\text { and puerperium } \\
\end{array}$ & $\begin{array}{l}\text { Review of English } \\
\text { literature }\end{array}$ & $\begin{array}{l}54 \text { pts with BAVM hemorrhage during } \\
1^{\text {st }} \text { trimester }(11 \%), 2^{\text {nd }} \text { trim }(44 \%), 3^{\text {rd }} \\
\text { trim }(41 \%) \text {, and post-partum }(4 \%) . \\
\text { Maternal mortality } 5 \% \text {. Maternal } \\
\text { dependence } 31 \% \text {. Fetal mortality } 2 \% \text {. }\end{array}$ & $\begin{array}{l}\text { Maternal mortality improved over } \\
\text { time compared to previous } \\
\text { systematic review. }\end{array}$ \\
\hline
\end{tabular}

